\title{
LC-ESI-MS/MS Analysis and Extraction Method of Phenolic Acids from Gluten-Free Precooked Buckwheat Pasta
}

\author{
Anna Oniszczuk ${ }^{1}$
}

Received: 6 February 2016 / Accepted: 16 March 2016/Published online: 2 April 2016

(C) The Author(s) 2016. This article is published with open access at Springerlink.com

\begin{abstract}
In many countries, common buckwheat (Fagopyrum esculentum Möench) has been cultivated for its nutritive value as food ingredient. This plant is a rich source of vitamins and exogenic amino acids. Many of the healthpromoting effects of $F$. esculentum have been attributed to a large amount of phenolic compounds. Presented in this paper, precooked buckwheat pasta, produced by extrusion cooking, is a gluten-free product without any technological additives. Moreover, it contains natural polyphenolic antioxidants and therefore could be classified as convenience food. The phenolic acid compositions of precooked buckwheat pasta were as follows: gallic, protocatechuic, gentisic, 4-OH-benzoic, vanillic, trans-caffeic, cis-caffeic, trans-p-coumaric, cis-pcoumaric, trans-ferulic, cis-ferulic, and salicylic. A very important step of sample pretreatment before quantitative analysis is the choice of extraction conditions. Therefore, in this study, before quantitative analysis (liquid chromatographymass spectrometry, LC-ESI-MS/MS), optimization of ultrasound-assisted extraction (UAE) of phenolic acids from precooked buckwheat pasta was performed. The most effective conditions for the isolation of phenolic acids from precooked buckwheat pasta with the use of UAE were as follows: $80 \%$ aqueous ethanol, $60^{\circ} \mathrm{C}$, ultrasound frequency $20 \mathrm{kHz}$, power $100 \mathrm{~W}$, and time $40 \mathrm{~min}$.
\end{abstract}

Keywords Fagopyrum esculentum Möench · Precooked buckwheat pasta $\cdot$ Ultrasound-assisted extraction $\cdot$ Phenolic

Anna Oniszczuk aoniszczuk@o2.pl

1 Department of Inorganic Chemistry, Medical University of Lublin, Chodźki 4a, 20-093 Lublin, Poland acids $\cdot$ High-performance liquid chromatography-mass spectrometry

\section{Introduction}

The genus Fagopyrum includes several species (Fu-hua et al. 2013; Morishita et al. 2007). Common buckwheat (Fagopyrum esculentum Möench) has been cultivated in many countries in Europe, Asia, South Africa, and USA for its nutritive value as food ingredient (Choi and Ma 2006; Kiprovski et al. 2015; Wu et al. 2015). Studies revealed that the consumption of buckwheat can reduce the blood glucose level (Kawa et al. 2003) cholesterol level (Inglett et al. 2010), provided protection from oxidative stresses (Mukoda et al. 2001; Przybylski et al. 1998), and showed antimutagenic activity (Yokozawa et al. 2002). This plant is a rich source of vitamins and exogenic amino acids (Kiprovski et al. 2015).

Many of the health-promoting effects of $F$. esculentum have been attributed to a large amount of phenolic compounds. Polyphenols are secondary plant metabolites, which show antibacterial, antiviral, anti-inflammatory, antiallergic, antithrombotic, and vasodilatory actions (Campillo et al. 2015; Oniszczuk and Podgórski 2015; Sharma et al. 2012; Tarola et al. 2013). They are applied in the prevention of cancer and cardiovascular diseases (Luthria and Mukhopadhyay 2006; Ness and Powles 1997).

Extrusion cooking seems to be one of the best methods for obtaining the maximum nutritive value of several plant materials. It is a high-temperature, short-time process, which combines the respective sequences of mixing, heating, shearing, forming, and shaping (Wójtowicz 2012). The first obtained precooked buckwheat pasta was produced by extrusion cooking in the Department of Food Process Engineering, 
University of Life Sciences in Lublin, as a gluten-free product without any technological additives.

An extremely significant step of sample pretreatment is the choice of extraction conditions. Therefore, in this study, before quantitative analysis (liquid chromatography-mass spectrometry, LC-ESI-MS/MS), optimization of ultrasoundassisted extraction of phenolic acids from precooked buckwheat pasta was performed.

\section{Materials and Methods}

\section{Chemicals and Plant Material}

Analytical grade standards of phenolic acids were purchased from Sigma-Aldrich Fine Chemicals (St. Louis, MO, USA). Liquid chromatography grade and analytical grade solvents were obtained from J.T. Baker (Phillipsburg, USA). Roasted buckwheat seeds (F. esculentum) were purchased from a local market (distributor Awiko, Lublin, Poland). Seeds were ground to flour (particle size below $500 \mu \mathrm{m}$ ).

\section{Pasta Processing}

Raw materials were moistened and mixed to obtain a moisture content of the dough at $32 \%$. After mixing, the raw materials were processed using a modified single-screw extrusion-cooker TS-45 (Metalchem, Gliwice, Poland) with $\mathrm{L} / \mathrm{D}=18: 1$ and compression ratio 3:1, equipped with an additional cooling section with glycol (chiller SW 8P MINI's Cool, Chotomów, Poland). Pasta products were shaped using a forming die with 12 openings with a diameter of $0.8 \mathrm{~mm}$ and processed at 100 rpm screw speeds.

\section{Ultrasound-assisted extraction}

Extraction was performed in an ultrasonic bath $(20 \mathrm{kHz}$, $100 \mathrm{~W}$; BANDELIN electronic GmbH \& Co. KG, Germany). Each 2-g portions of the powdered sample was extracted with $40 \mathrm{~mL}$ of $80 \%$ aqueous methanol $(80 \%$ $\mathrm{MeOH})$ or $80 \%$ aqueous ethanol $(80 \% \mathrm{EtOH})$ for $40 \mathrm{~min}$ (two cycles for $20 \mathrm{~min}$ ) at $60^{\circ} \mathrm{C}$ (Oniszczuk and Olech 2016). Extraction temperature was adjusted to 55,60 , or $65{ }^{\circ} \mathrm{C}$. Extracts were filtered, combined, and evaporated to dryness. The residues were dissolved in $5 \mathrm{~mL}$ of methanol. The procedure was repeated three times for every condition.

\section{LC-ESI-MS/MS Analysis of Phenolic Acids}

The samples were analyzed by high-performance liquid chromatography and electrospray ionization mass spectrometry (HPLC-ESI-MS/MS) according to the method described previously (Oniszczuk and Olech 2016). Analysis was performed

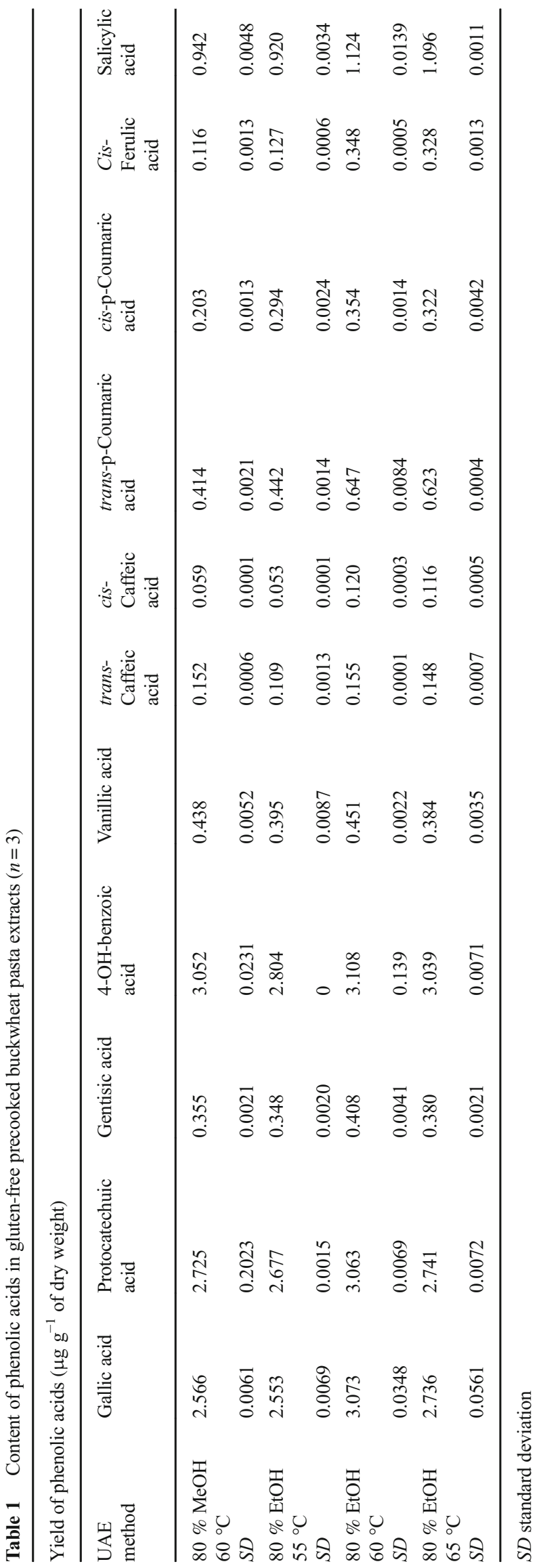


using Agilent 1200 Series HPLC (Agilent Technologies, USA) equipped with a binary gradient solvent pump, a degasser, an autosampler, and a column oven. Phenolic acids were separated at $25{ }^{\circ} \mathrm{C}$, on a Zorbax SB-C18 column $(2.1 \times 50 \mathrm{~mm}, 1.8-\mu \mathrm{m}$ particle size; Agilent Technologies, USA), using $3-\mu \mathrm{L}$ injections. The solvents used were as follows: water containing $0.1 \% \mathrm{HCOOH}$ (solvent $\mathrm{A}$ ) and methanol containing $0.1 \% \mathrm{HCOOH}$ (solvent B). The following gradient elution program at a flow rate of $400 \mu \mathrm{L} \mathrm{min}{ }^{-1}$ was applied: 0-1 $\mathrm{min}, 5 \% \mathrm{~B} ; 2-4 \mathrm{~min}, 20 \% \mathrm{~B} ; 8-9.5 \mathrm{~min}, 70 \%$ B; 11.5-15 min, $5 \%$ B. MS detection was performed in a 3200 QTRAP mass spectrometer (AB Sciex, USA) equipped with an electrospray ionization source (ESI) and a triple quadrupole-ion trap mass analyzer that was controlled by the Analyst 1.5 software. The ESI interface was operated in the negative-ion mode.

The correlation coefficient of all calibration curves was $R^{2}>0.9992$. Analytical results and parameters of LC-MS/ MS quantitative method - data for calibration curves, limit of detection (LOD) and the limit of quantification (LOQ)
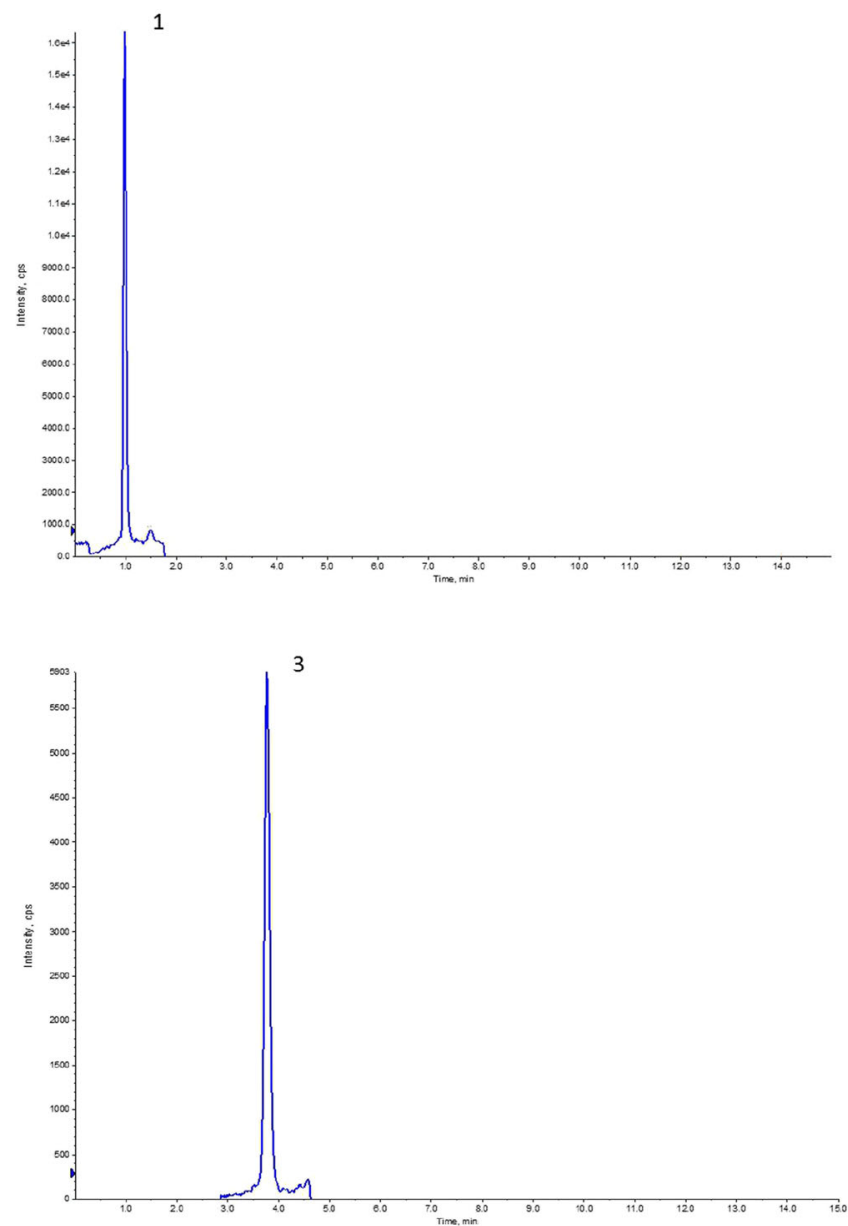

Fig. 1 LC-ESI-MS/MS chromatogram of phenolic acids from precooked buckwheat pasta. Extraction method: UAE, $60^{\circ} \mathrm{C}$, ultrasound frequency $20 \mathrm{kHz}$, power $100 \mathrm{~W}$, time $40 \mathrm{~min}, 80 \%$ aqueous ethanol. Acids: 1 values for each analyzed phenolic acids-are presented in the paper described previously (Oniszczuk and Olech 2016).

\section{Results and Discussion}

The phenolic acid compositions of precooked buckwheat pasta were as follows: gallic, protocatechuic, gentisic, 4-OHbenzoic, vanillic, trans-caffeic, cis-caffeic, trans-p-coumaric, cis-p-coumaric, trans-ferulic (content lower than LOQ, but higher than LOD), cis-ferulic, and salicylic (Table 1, Fig. 1).

Optimization of extraction solvent was the first step of the experiment. In order to achieve this, $80 \%$ aqueous ethanol and $80 \%$ aqueous methanol were used. Eighty percent of EtOH appears to be the superior extractant for the isolation of analyzed compounds from buckwheat pasta. This solvent meets the requirements of "Green Chemistry" (Chemat et al. 2008) and offers several advantages, for example, insignificant toxicity and environmental
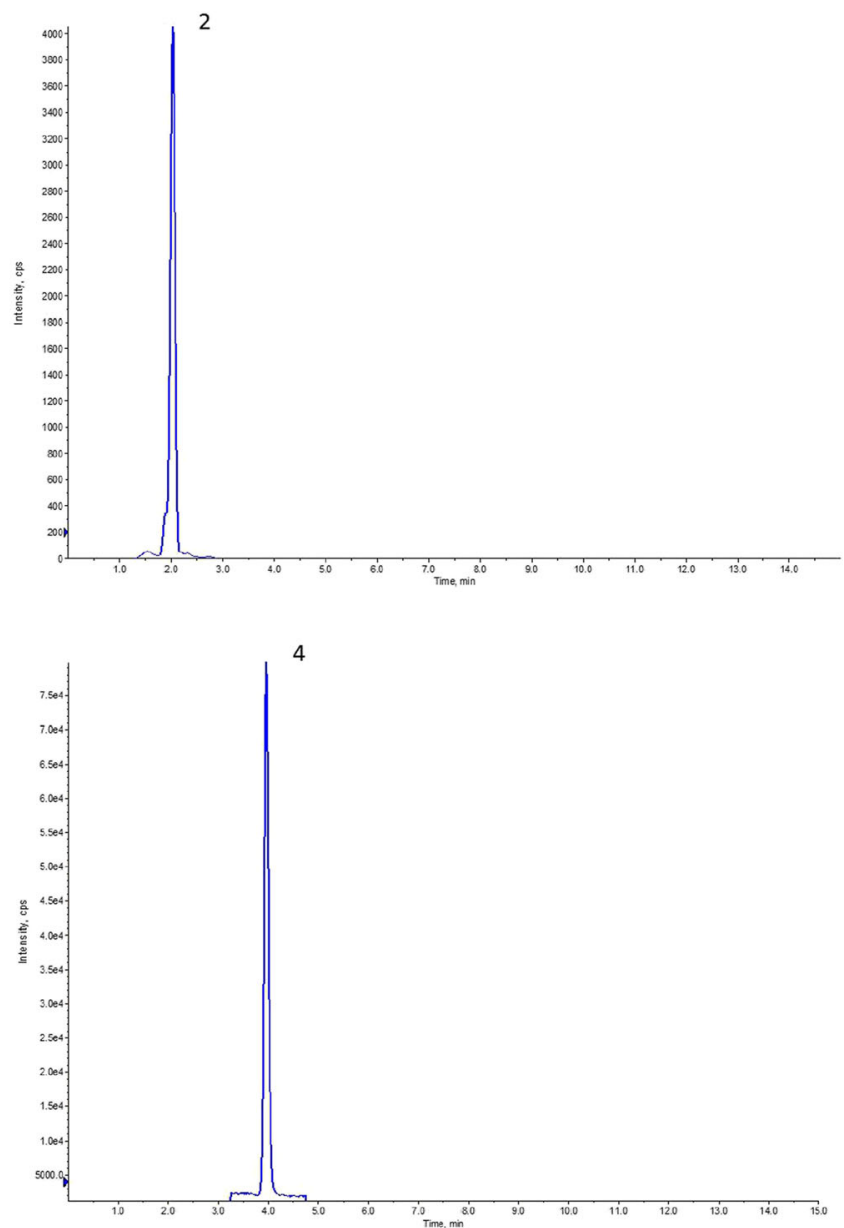

gallic, 2 protocatechuic, 3 gentisic, 44-OH-benzoic, 5 vanillic, 6 transcaffeic, 7 cis-caffeic, 8 trans-p-coumaric, 9 cis-p-coumaric, 10 transferulic, $11 \mathrm{cis}$-ferulic, 12 salicylic 

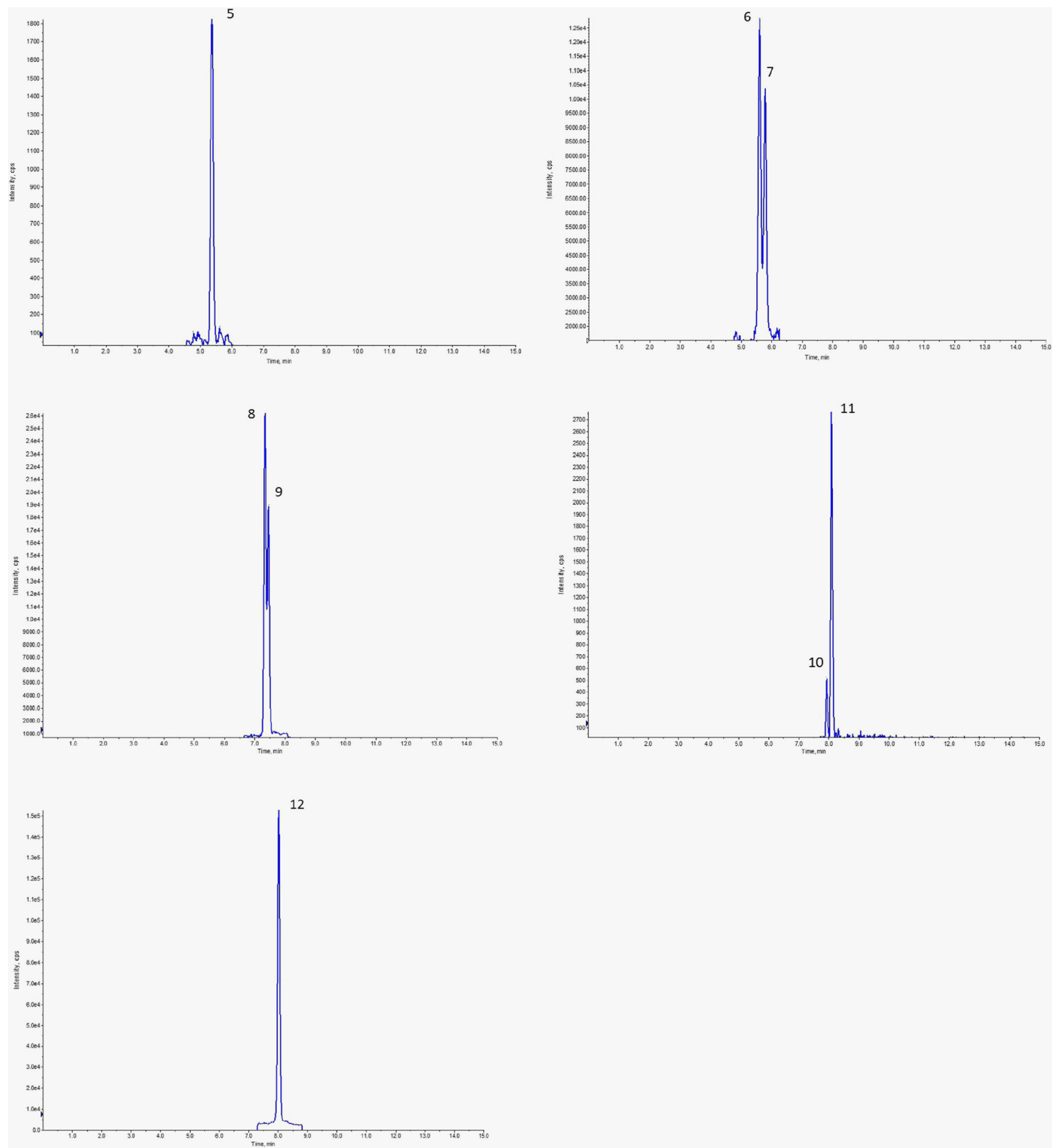

Fig. 1 (continued)

compatibility. Due to the polar nature of the phenolic acids, the addition of water $(20 \% v / v)$ to organic solvent increases the extraction yield (Oniszczuk and Olech 2016). Gallardo et al. reported slightly lower levels of phenolic compounds in aqueous extract compared to $80 \%$ methanolic extract from buckwheat flour (Gallardo et al. 2006). In contrast, other researchers have found that $80 \%$ methanol extracted
64 times more phenolic compounds than did water (Zielinski and Kozlowska 2000).

The next step was optimization of the extraction temperature using $80 \%$ aqueous ethanol as extractant. The increase of temperature from 55 to $60{ }^{\circ} \mathrm{C}$ improves efficiency of the process, whereas the further increase of temperature reduces the efficiency of extraction. It can be supposed that higher 
temperature (and cavitation in this condition) caused the degradation of phenolic acids (Boonkird et al. 2008).

The accuracy of the method was evaluated through recovery studies. The samples moistened with the solvent were spiked with known amounts of each standard solution (three concentration levels). Afterward, UAE was carried out using the same ways employed in the quantitative determination of phenolic compounds in the samples. The recoveries were in the range of $88.9 \%$ (for cis-p-coumaric acid) to $97.3 \%$ (for salicylic acid); therefore, UAE can be considered as an accurate method.

A short time of quantitative extraction of analyzed compounds results from the fact that polyphenols are presented in buckwheat seeds in the free form. In contrast, polyphenols of other cereal grains are primarily bound to cell wall components (Adom and Liu 2002). Such complexes are difficult to break down, and diffusion of solvent into these materials requires drastic extraction conditions and long extraction time (Oniszczuk et al. 2014).

Buckwheat products play an important role in the nutrition of people with gluten intolerance and other problems of the digestive track. Nowadays, people are looking for functional foods that are both tasty and having pro-healthy properties. The above research results indicated that extrusion cooking is a method, which provides a high content of active polyphenols in products. Precooked buckwheat pasta, due to the presence of high levels of phenolic acids, ensures health benefits, beyond the nutrition aspects. Extrusion cooking provides stable products with all nutritive components preserved or enhanced by the application of natural, biologically active compounds.

\section{Conclusions}

Precooked buckwheat pasta, due to the presence of high levels of phenolic acids, ensures health benefits, beyond the nutrition aspects. It contains natural polyphenolic antioxidants and therefore could be classified as convenience food. The phenolic acid compositions of the product were as follows: gallic, protocatechuic, gentisic, 4-OH-benzoic, vanillic, trans-caffeic, cis-caffeic, trans-p- coumaric, cis-p-coumaric, transferulic, cis-ferulic, and salicylic.

The solvent type and extraction temperature influenced extraction yield under ultrasound treatment. The most effective conditions for the isolation of phenolic acids with the use of UAE were as follows: $80 \%$ aqueous ethanol, $60{ }^{\circ} \mathrm{C}$, ultrasound frequency $20 \mathrm{kHz}$, power $100 \mathrm{~W}$, and time $40 \mathrm{~min}$.

\section{Compliance with Ethical Standards}

Funding This study was supported by the Medical University of Lublin.
Conflict of Interest Anna Oniszczuk declares that she has no conflict of interest.

Ethical Approval This article does not contain any studies with human or animal subjects.

Informed Consent Not applicable.

Open Access This article is distributed under the terms of the Creative Commons Attribution 4.0 International License (http:// creativecommons.org/licenses/by/4.0/), which permits unrestricted use, distribution, and reproduction in any medium, provided you give appropriate credit to the original author(s) and the source, provide a link to the Creative Commons license, and indicate if changes were made.

\section{References}

Adom KK, Liu RH (2002) Antioxidant activity of grains. J Agric Food Chem 50:6182-6187

Boonkird S, Phisalaphong C, Phisalaphong M (2008) Ultrasoundassisted extraction of capsaicinoids from Capsicum frutescens on a lab- and pilot-plant scale. Ultrason Sonochem 15:1075-1079

Campillo N, Viñas P, Férez-Melgarejo G, Ochotorena ML, HernándezCórdob M (2015) Determination of phenolic acids and hydrolyzable tannins in pomegranate fruit and beverages by liquid chromatography with diode array detection and time-of-flight mass spectrometry. Food Anal Methods 8:1315-1325

Chemat F, Tomao V, Virot M (2008) Ultrasound-assisted extraction in food analysis. In: Ötles S (ed) Handbook of food analysis instruments. CRC press, Boca Raton

Choi S-M, Ma C-Y (2006) Extraction, purification and characterization of globulin from common buckwheat (Fagopyrum esculentum Moench) seeds. Food Res Int 39:974-981

Fu-hua L, Ya Y, Xiao-lan Y, Shu-ying T, Jian M (2013) Phenolic profiles and antioxidant activity of buckwheat (Fagopyrum esculentum Möench and Fagopyrum tartaricum L. Gaerth) hulls, brans and flours. J Integr Agric 12:1684-1693

Gallardo C, Jimenez L, Garcia-Conesa MT (2006) Hydroxycinnamic acid composition and in vitro antioxidant activity of selected grain fractions. Food Chem 99:455-463

Inglett GE, Rose DJ, Chen D, Stevenson DG, Biswas A (2010) Phenolic content and antioxidant activity of extracts from whole buckwheat (Fagopyrum esculentum Möench) with or without microwave irradiation. Food Chem 119:1216-1219

Kawa JM, Taylor CG, Przybylski R (2003) Buckwheat concentrate reduces serum glucose in streptozotocin-diabetic rats. J Agric Food Chem 51:7287-7291

Kiprovski B, Mikulic-Petkovsek M, Slatnar A, Veberic R, Stampar F, Malencic D, Latkovic D (2015) Comparison of phenolic profiles and antioxidant properties of European Fagopyrum esculentum cultivars. Food Chem 185:41-47

Luthria DL, Mukhopadhyay S (2006) Influence of sample preparation on assay of phenolic acids from eggplant. J Agric Food Chem 54:41-47

Morishita T, Yamaguchi H, Konosuke D (2007) The contribution of polyphenols to antioxidative activity in common buckwheat and tartary buckwheat grain. Plant Prod Sci 10:99-104

Mukoda T, Sun B, Ishiguro A (2001) Antioxidant activities of buckwheat hull extract toward various oxidative stress in vitro and in vivo. Biol Pharm Bull 24:209-213

Ness AR, Powles JW (1997) Fruit and vegetables, and cardiovascular disease: a review. Int J Epidemiol 26:1-13 
Oniszczuk A, Olech M (2016) Optimization of ultrasound-assisted extraction and LC-ESI-MS/MS analysis of phenolic acids from Brassica oleracea L. var. sabellica. Ind Crop Prod 83:359-363

Oniszczuk A, Podgórski R (2015) Influence of different extraction methods on the quantification of selected flavonoids and phenolic acids from Tilia cordata inflorescence. Ind Crop Prod 76:509-514

Oniszczuk A, Podgórski R, Oniszczuk T, Żukiewicz-Sobczak W, Nowak R, Waksmundzka-Hajnos M (2014) Extraction methods for the determination of phenolic compounds from Equisetum arvense L. herb. Ind Crop Prod 61:377-381

Przybylski R, Lee YC, Eskin NAM (1998) Antioxidant and radicalscavenging activities of buckwheat seed components. J Am Oil Chem Soc 75:1595-1601

Sharma P, Ghimeray AK, Gurung A, Jin CW, Rho HS, Cho DH (2012) Phenolic contents, antioxidant and $\alpha$-glucosidase inhibition properties of Nepalese strain buckwheat vegetables. Afr J Biotechnol 11: 184-190
Tarola AM, Van de Velde F, Salvagni L, Preti R (2013) Determination of phenolic compounds in strawberries (Fragaria ananassa Duch) by high performance liquid chromatography with diode array detection. Food Anal Methods 6:227-237

Wójtowicz A (2012) Influence of process conditions on selected texture properties of precooked buckwheat pasta. Teka 12:315-322

Wu X, Ge X, Liang S, Lv Y, Sun HA (2015) Novel selective accelerated solvent extraction for effective separation and rapid simultaneous determination of six anthraquinones in tartary buckwheat and its products by UPLC-DAD. Food Anal Methods 8:1124-1132

Yokozawa T, Kim HY, Nonaka G, Kosuna K (2002) Buckwheat extract inhibits progression of renal failure. J Agric Food Chem 50:33413345

Zielinski H, Kozlowska H (2000) Antioxidant activity and total phenolics in selected cereal grains and their different morphological fractions. J Agric Food Chem 48:2008-2016 